Article

\title{
Characteristics of the Digital Content about Energy-Saving in Different Countries around the World
}

\author{
Gabriel Valerio-Ureña ${ }^{1, *(1)}$ and Richard Rogers ${ }^{2}$ \\ 1 School of Humanities and Education, Tecnológico de Monterrey, Monterrey 64700, Mexico \\ 2 Department of Media Studies, University of Amsterdam, 1012XT Amsterdam, The Netherlands \\ * Correspondence: gvalerio@tec.mx
}

Received: 26 June 2019; Accepted: 9 August 2019; Published: 29 August 2019

check for updates

\begin{abstract}
Environmental sustainability is fundamental for human well-being, and energy-saving behaviors are fundamental for promoting environmental sustainability. This paper explores the types of information consumed on the Internet concerning the topic of energy-saving. The qualitative study used digital methods to analyze, from 17 different countries, one-year of Google searches, 170 webpages, and 6800 images. The results demonstrated that (a) most topics related to energy-saving involved commercial products; (b) in countries from North America, Europe, and Oceania, Google's highest-ranked webpages were of a commercial nature, and in countries from Latin America, Africa, and Asia, webpages were of an educational nature; and (c) most images found in Google with the "energy-saving" query were related to lighting products. By and large, commercial interests were found to dominate the digital rhetoric around energy-saving, regardless of the countries' region.
\end{abstract}

Keywords: energy-saving behavior; digital content; digital methods; Google Search; image analysis

\section{Introduction}

The environment is fundamental for covering basic needs, as well as for improving well-being [1] and energy-saving behaviors that are fundamental for promoting environmental sustainability. Considering how pervasive the Internet and other information technologies have become in our lives, understanding energy-saving behaviors also requires analyzing our digital footprint. Nowadays, many aspects of our social life are codified [2,3]. According to Brunn, in an electronic information world, electronic bits or bytes of information probably represent the best sources to learn how much is 'out there' about a given subject. Additionally, it is a legitimate context within which to study intersecting human/environment relations, including sustainability in disciplinary and interdisciplinary frameworks [4].

With this in mind, the objective of this paper was to identify the characteristics of digital content (searches, images, and webpages) that people produce (searches) and consume (images and webpages) on the Internet, regarding the topic of energy-saving, in some countries around the world. Analyzing the characteristics of the Internet content about energy-saving can greatly contribute to identifying the perception of people about energy-saving and this can provide valuable insight into how we may bolster relevant environment protection, governance, and policy-making.

The biophilia hypothesis proclaims a human dependency on nature that extends beyond the need for material sustenance toward the need for an aesthetic, intellectual, cognitive, spiritual, and fulfillment meaning [5]. Biophilia proposes that "there is an evolutionary and biological need for contact with nature, even when we have become very clever at believing we can live without it. Nature in our lives is not optional but essential" [6]. 
The Organisation for Economic Co-operation and Development (OECD) [1] has asserted that our local living environment has a direct impact on our health and well-being; an unspoiled environment is a source of satisfaction, improves mental well-being, and allows people to recover from the stress of everyday life and to perform physical activity. Therefore, it is of great importance that we regard the protection of our environment and natural resources as an intergenerational and long-term priority. The Intergovernmental Panel on Climate Change estimated that changes in lifestyle and daily behavioral practices could reduce the energy demand by up to $20 \%$ in the short-term and $50 \%$ in the long-term in developed countries [7].

Pro-environmental behavior is a multidimensional concept that can be defined in terms of conservational attitudes, moral beliefs, economic development, and energy-saving and production, as well as planning and social well-being; it includes considering intentional behaviors, habits, or obligations. Many researchers have examined the factors that influence pro-environmental actions, such as energy-saving behavior [8], which include economic benefits, governmental policies, propaganda, perceived inconvenience, environmental knowledge, promoting energy-saving, cost, environmental information, and social exchange. Pro-environmental behaviors can be positively or negatively influenced by demographic factors, external factors (e.g., institutional, economic, social, and cultural), and internal factors (e.g., motivation, environmental knowledge, awareness, values, attitudes, emotion, locus of control, responsibilities, and priorities) [9].

When discussing pro-environmental attitudes and behaviors, it is important to consider the related term "sustainability". The Commission on Sustainable Development defined sustainable development as "development that meets the needs of the present without compromising the ability of future generations to meet their own needs" [10]. The concept of sustainability has evolved over time, and its definition is currently rooted in both social and ecologic systems that are primarily focused on social, environmental, and economic pillars [11]. The social dimension is centered on culture, responsibility, social organizations, and the moral norms of behavior and well-being, whereas the environmental field focuses on growing concerns for the protection of the environment and its natural resources (e.g., the atmosphere, hydric systems, and territorial expansion). Finally, the economic aspects of sustainability are concerned with the optimal handling of natural resources and their production, agriculture, household resources, industry, and transport services. This element is prominent in the agendas of developing countries, and its market is growing with the emergence of different energy-saving and production strategies.

Although the natural environment and sustainability are essential to preserving life and increasing human well-being, it often appears as though we are not fully aware of their vulnerabilities. Energy-saving is a pro-environmental behavior that could help in the battle against planetary devastation and many people have already implemented measures in their daily lives. However, given the dynamics of today's society, it is difficult to discern whether people's interest in energy-saving derives from a desire to conserve the planet or that of saving money. In addition, it is important to identify the type of content that people access on the Internet when they have an interest in "energy-saving", because it largely depends on the search engine algorithms, as well as on the design of the Web pages that are retrieved by them (Search Engine Optimization).

Search Engine Optimization (SEO) is a process whereby the visibility of a webpage or website increases in the search results. This process is crucial for online marketing and, hence, impacts on the success of any business [12]. Some examples of popular SEO guidelines and their percentage of the search market share worldwide are those of Google (92.62\%), Bing (4.26\% worldwide), Yahoo (2.35\%), and DuckDuckGo $(0.76 \%)[13,14]$. These SEOs underscore the uniqueness of content, meta-data, navigation, and a human-centric web design [15]. SEO works by retrieving a list of website links that match the search of a word or phrase. Before retrieving those results, the search engine must perform actions such as crawling, indexing, processing, and ordering, and different types of search results can be provided by the search engine. Search results include organic or natural search results, paid ads, and blended results. Organic or natural search results comprise those that are the product of the search 
engine ranking algorithm. Blended results are the product of the location of the searcher, and they include videos, images, maps, and news, among others [11].

In this research, we employed digital methods to identify the characteristics of searches and digital content (images and webpages) that people (from different countries around the world) found when they searched for "energy-saving" on the Internet.

Rogers [16] has defined digital methods as techniques used for the study of social and cultural phenomena that make use of the data available on the web (e.g., digital objects such as websites, uniform resource locators (URL), hyperlinks, tags, likes, tweets, content managers, blogs, social networking websites, search engines and directories, and many other devices that have originated from various Internet platforms). Digital methods consider the ways in which the web organizes its data through the exploration of "natively digital objects" [17] (i.e., things that are only found on the web), and analyze them with techniques that are only employed for web data to better understand the organization of the web [18]. In this research, we use three different kinds of digital objects, namely search queries, webpages, and images.

As a form of data, Internet search queries play an instrumental role in the construction of public knowledge. Moreover, commercial search engines have become critical sources of news and information and have thus acquired a vital place in contemporary knowledge dissemination. According to Granka, as these tools enable people to delve into any issue of interest, academics have suggested that Internet searches could be employed as behavioral measures of an individual's interest in an issue. Besides its cost-cutting benefits, other advantages of this approach include that an analysis of Internet search trends provides unobserved, dynamic, real-time insight into public attention to issues, as well as behavior at the aggregate level. They also eliminate traditional bias such as telescoping, memory decay, and desirable answers [19].

With the pervasiveness of computers and smartphones in our daily lives, real-time searches and the almost immediate obtainment of information through Internet queries is becoming more popular [20]. Google Search is the most used web search engine worldwide, and from January 2018 to September of the same year, Google represented $72.67 \%$ of all desktop-based search queries and $80.34 \%$ of all mobile-based search queries [21].

In this work, we used Google Trends to analyze search queries: a big-data based, no-fee website service that displays the frequency of a keyword based on global searches in real-time. Given that queries entered into the Google search engine represent the complete spectrum of user interest, it is foreseeable that Google Trends data could be used to analyze a wide variety of social, cultural, or political phenomena [22]. Google Trends enables estimations of driving factors that would otherwise be difficult to uncover when analyzing different indicators, and it has the capability to "predict the present" or analyze information that has not been announced and cannot otherwise be analyzed officially. The data acquired from this website follows a normal distribution and displays fixed maximum and minimum values that change in relation to the region or period [20]. However, this tool has some limitations, including the uncertainty of the characteristics of the person conducting the query and the underlying reasons for their searches [15], and the results are subject to distorted patterns caused by moral panic searches and trivial matters, such as misspellings in search bars [19]. In any case, the results of these searches include all kinds of digital content, including complete Web pages and specific images.

Moreover, as a part of this research, we analyzed the images recovered by those queries. In this case, we use Google Cloud Vision, an image recognition technology that enables users to remotely process the content of an image and retrieve its main features [23]. Launched in February of 2016 [24], the tool enables access to image classification algorithms that were built with very large training sets and provides features such as face detection, optical character recognition, label detection, SafeSearch detection, landmark detection, logo detection, and properties detection [23,24]. After an image is uploaded to the Application Programming Interface (API), the label detection feature returns a list of labels for the image, along with a confidence score for each label. The main inconvenience of this API 
is that the addition of noise could cause it to provide irrelevant labels as the output or fail to detect faces or text within the image; however, applying noise filters to the input could improve the system's robustness without the need for updating the image analysis algorithms [25].

Analyzing the digital content people found on the Internet when looking for information on energy-saving can greatly contribute to recognizing their perception about the relationship between energy-saving and sustainability. That is why the general question of this paper is the following: What are the characteristics of the digital content (searches, images, and webpages) that people in specific countries around the world produce and consume on the Internet regarding the topic of energy-saving?

\section{Materials and Methods}

\subsection{Research Questions}

This explorative research aimed to identify the characteristics of digital content (searches, images, and webpages) that people produce and consume on the Internet, regarding the topic of energy-saving, around the world. Given the nature of the subject, a qualitative study was proposed. The research questions that guided this study are elucidated below:

1. What are the topics more related to the query "energy-saving" that people search for on Google in different countries? The assumption informing this question was that the topics related to the query for "energy-saving" in different countries can, in some proportion, reflect the topics with which Google users relate the issue of energy-saving in each of the different countries. Information provided by Google Trends was used to answer the question, and the results of the query were grouped by region;

2. What are the kinds of webpages that people found when they look for "energy-saving" on Google in the different countries? The assumption of this question is that the ranking that Google displays of different kinds of sites can, to some extent, reflect the level of access to information on these sites in the respective countries. This variable is important in that it can provide clues about the type of information that each country consumes when conducting the query "energy-saving";

3. What are the kinds of images that people found when they looked for "energy-saving" on Google in the different countries? The premise of this question is that the best-ranked images from Google Search can be an indicator of the type of information that is most often related to the topic of energy-saving in different countries.

\subsection{Participants}

In order to verify that taking care of the environment was a priority for the countries considered for the study, the basic criterion for selecting the participant was: all English and Spanish speaking countries, with more than 250 responses in the OECD's Better Life Index, including the environmental attribute. For selecting the participants, we accessed (July 2018) the OECD's Better Life Index website (http://www.oecdbetterlifeindex.org). The countries that fulfilled this criterion were the United States, United Kingdom, Australia, Ireland, New Zealand, Canada, South Africa, Hong Kong, India, Singapore, Peru, Argentina, Venezuela, Colombia, Mexico, Chile, Costa Rica, and Spain. Because Costa Rica did not have sufficient search data in the Google Trends registry, this country was excluded from the sample. The limitation of the languages addresses the requirement of the language domain for the data analysis.

The general distributions of the sample $(n=17)$ can be described as below:

- $\quad$ By region: Asia (3); Europe (3); Latin America (6); North America (2); Oceania (2); Africa (1)

- $\quad$ By language: English (10); Spanish (7)

The level of importance (rank of the environment among the 11 OECD factors for well-being/importance given to the factor) distributions of the sample are elucidated below: 
- By region: North America (5.5/9.08\%); Europe (7/8.78\%); Oceania (7/8.67\%); Latin America (7.67/8.80\%); Asia (8.33/8.83\%); Africa (9/8.84\%)

- $\quad$ By language: English (7.3/8.85\%); Spanish (7.57/8.78\%)

It is important to clarify that the number assigned in the ranking represents the relative position of the environment on a scale of importance among the 11 factors established by the OECD for well-being (from 1 to 11 , where 1 is the most important and 11 is the least important). The value assigned refers to how important the participating countries consider this factor for their well-being compared to other factors on the list.

A review of these distributions shows a relatively wide range of importance attributed to the environment. Whereas the environment ranks in the middle of the 11 factors in North America, in Asia, the environmental factor falls to 8th place (8.33 on average), and in Africa, the environment is ranked near the bottom of all priorities. Table 1 shows a list of all the countries that were sampled for this study.

Table 1. Participant countries and level of importance given to the environment on the OECD Better Life Index.

\begin{tabular}{lccccc}
\hline$\#$ & Country & Language & Region & Environment Importance & Position of Importance \\
\hline 1 & Argentina & Spanish & Latin America & $8.76 \%$ & 8 \\
2 & Australia & English & Oceania & $7.92 \%$ & 9 \\
3 & Canada & English & North America & $9.03 \%$ & 6 \\
4 & Chile & Spanish & Latin America & $9.14 \%$ & 6 \\
5 & Colombia & Spanish & Latin America & $9.07 \%$ & 6 \\
6 & Hong Kong & English & Asia & $8.75 \%$ & 9 \\
7 & India & English & Asia & $8.83 \%$ & 8 \\
8 & Ireland & English & Europe & $8.62 \%$ & 8 \\
9 & Mexico & Spanish & Latin America & $8.78 \%$ & 9 \\
10 & New Zealand & English & Oceania & $9.42 \%$ & 5 \\
11 & Peru & Spanish & Latin America & $8.74 \%$ & 8 \\
12 & Singapore & English & Asia & $8.91 \%$ & 8 \\
13 & South Africa & English & Africa & $8.84 \%$ & 9 \\
14 & Spain & Spanish & Europe & $8.67 \%$ & 7 \\
15 & United Kingdom & English & Europe & $9.06 \%$ & 6 \\
16 & United States & English & North America & $9.13 \%$ & 5 \\
17 & Venezuela & Spanish & Latin America & $8.28 \%$ & 9 \\
\hline
\end{tabular}

\subsection{Procedure}

Before performing the analysis, the cookies of the search engines were deleted, and any personal Google accounts stored on the laptops were logged out. This was done with the aim of using a clean version of Google as a research tool and reducing the impacts of the researcher's profile on the results [10,11].

For recognizing this research, the keyword "energy-saving" was selected for its popularity as a measure of interest to understand the energy-saving and well-being phenomena. The analysis targeted the following features:

1. Topics on Google Trends related to the query "energy-saving." This refers to terms associated with the query "energy-saving" or "Ahorro de energía" (for the queries in Spanish) according to Google Trends. To obtain these values, we accessed https://rends.google.com/trends/, customized the query for each country of the sample, and limited the span to the year 2017 for the web search. Once we had obtained the results, we integrated them into the three levels of analysis (per country, general, and region);

2. Types of Webpages found when searching "energy-saving" on Google. This category comprises the types of websites that were found using Google Advanced Search. To do that, we accessed the site https://www.google.com/advanced_search, selected the language and region, and then ran the query "Energy-saving" or "Ahorro de energía" (for the queries in Spanish). The first 10 websites were selected from the results in order of importance, and the type of site was manually analyzed 
and classified under the following categories: (a) Educational; (b) commercial; (c) non-profit organizations; (d) media; (e) government; and (f) Wikipedia. We then integrated the results into the three levels of analysis (per country, general, and region);

3. Characteristics of images found by Google Search with the keyword "energy-saving." This category refers to the features shared by the top 400 images that users obtain when they search "energy-saving" for a specific country. The query "energy-saving" was searched in Google Images (advanced search) with the specific language and country for each member of the sample. Afterward, the top 400 images returned by Google were downloaded using the Chrome extension GetThemAll. Images unrelated to the search (i.e., the Google logo) were discarded. Then, the images were labeled with Cloud Vision, using the Application Programming Interface (API) memespector-python [26]. Figure 1 shows a real example of how Google Cloud Vision identifies the characteristics of a specific image. Later, to reduce the possible wrong labels that could be given as the output [27], the complete list of labels was reviewed manually and those found to be irrelevant were removed. Thereupon, the most representative labels ( 95 percentile) were identified, and the constant comparison method was employed to identify the main categories found on labels. Finally, manual categorization of a sample of the first 50 images of each country $(\mathrm{n}=1450)$ was conducted.

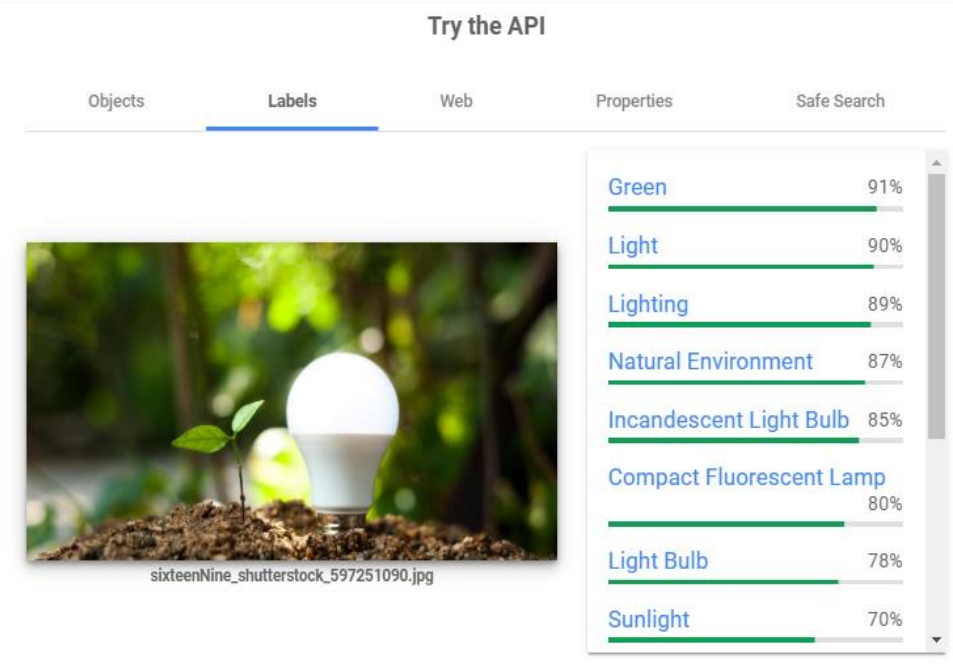

Figure 1. Example of labeling with Google Cloud Vision.

\section{Results}

In order to answer the three research questions, the results by country were grouped by their region of origin.

\subsection{What Are the Topics More Related to the Query "Energy-Saving" That People Search on Google in the Different Countries?}

Without taking into account the region, by and large, the results show that the majority of topics are more related to (a) general topics related to energy-saving (e.g., energy conservation, energy efficiency, efficient energy use, electric energy, day, and electricity); (b) commercial products which, by their acquisition or change, could help to save energy (e.g., incandescent light bulbs, light-emitting diodes, lighting, air conditioning, and computer monitors); and (c) topics related to economic savings (e.g., money, coupons, and consuming). Notably, water was the only specific topic related to the environment.

Table 2 displays the results grouped by region. The number, next to each topic, corresponds to the extent to which users seeking the term "energy-saving" also seek those specific terms; the score is based on a relative escalation in which 100 is the most searched topic and 50 is the subject that is searched with half the frequency. 
Table 2. Google Trends-related topics by region.

\begin{tabular}{|c|c|c|c|c|c|c|c|c|c|c|c|c|c|c|c|c|c|c|c|c|c|c|c|}
\hline Topic & 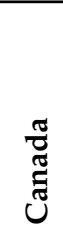 & 岕 & 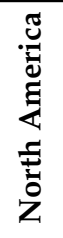 & $\begin{array}{l}\text { हैँ } \\
\text { के }\end{array}$ & 光 & 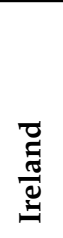 & 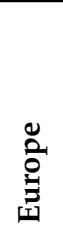 & 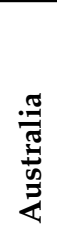 & 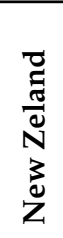 & Oّٓ & 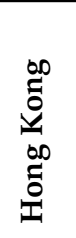 & $\underset{\Xi}{\tilde{\Xi}}$ & 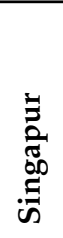 & $\frac{\pi}{\frac{\pi}{2}}$ & 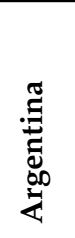 & 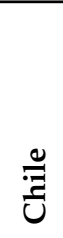 & $\frac{.00}{0}$ & 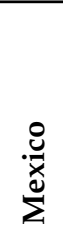 & $\underset{d}{E}$ & 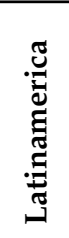 & 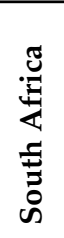 & 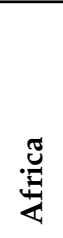 & 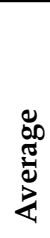 \\
\hline Energy conservation & 88 & 89 & 89 & & 81 & 100 & 91 & 75 & 86 & 81 & 100 & 84 & 55 & 80 & & & & & & & 94 & 94 & 85 \\
\hline Energy efficiency & & & & 53 & & & 53 & & & & & & & & 93 & 33 & 74 & 70 & 50 & 64 & & & 61 \\
\hline Saving & 21 & 17 & 19 & 67 & 37 & 6 & 37 & 13 & 7 & 10 & 11 & 20 & 9 & 13 & 100 & 67 & 96 & 74 & 75 & 82 & 12 & 12 & 38 \\
\hline Electric energy & & & & & & & & & & & & & & & & & & 18 & 12 & 15 & & & 15 \\
\hline Lighting & 11 & 16 & 14 & & 26 & 19 & 23 & 12 & 21 & 17 & & 5 & 9 & 7 & & & & & & & 15 & 15 & 15 \\
\hline Money & & 4 & 4 & & 25 & & 25 & & & & & & & & & & & & & & & & 15 \\
\hline Incandescent light bulb & 5 & 16 & 11 & & 31 & 12 & 22 & 8 & 21 & 15 & & & 9 & 9 & & & & & & & 6 & 6 & 14 \\
\hline Electricity & 5 & 6 & 6 & & 5 & & 5 & 5 & & 5 & & 6 & 9 & 8 & & & 15 & 15 & 6 & 12 & 6 & 6 & 8 \\
\hline Coupon & 10 & & 10 & & & & & & & & & & & & & & & & & & & & 10 \\
\hline Water & & & & & & & & 7 & & 7 & & & 6 & 6 & & & 18 & & 6 & 12 & & & 9 \\
\hline Air conditioning & & 6 & 6 & & & & & 5 & & 5 & & 4 & 15 & 10 & & & & & & & & & 7 \\
\hline Office & & & & & & & & & & & & 7 & & 7 & & & & & & & & & 7 \\
\hline Consuming & & & & 7 & & & 7 & & & & & & & & & & & 6 & & 6 & & & 7 \\
\hline Water heating & & & & & & & & & & & & & 6 & 6 & & & & & & & & & 6 \\
\hline Refrigerator & & 3 & 3 & & & & & 3 & & 3 & & & 12 & 12 & & & & & & & & & 6 \\
\hline Power inverter & & & & & & & & & & & & & 6 & 6 & & & & & & & & & 6 \\
\hline Watt & & & & & 5 & & 5 & & & & & & & & & & & & & & 6 & 6 & 5 \\
\hline Light-emitting diode & 5 & 6 & 6 & & 6 & 6 & 6 & 5 & 7 & 6 & & & 6 & 6 & & & & & & & 3 & 3 & 6 \\
\hline Efficient energy use & 8 & 5 & 7 & & 2 & & 2 & 9 & & 9 & & 6 & 3 & 5 & & & & & & & 3 & 3 & 5 \\
\hline Home & 4 & 5 & 5 & & & & & 6 & & 6 & & & & & & & & & & & & & 5 \\
\hline
\end{tabular}


The topics "energy conservation," "incandescent light bulbs," and "lighting" appear to be strongly related to "energy-saving" in all regions except Latin America. On the other hand, the topic of energy efficiency is robustly related to the topic of energy-saving in Latin America and Spain. Furthermore, the topic "energy-saving" was found to be related to the word "money" in both the US and UK; similarly, the topic "light-emitting diodes" was present in North America, Europe, and Oceania. Finally, the topic "water" was only found in Australia, Singapore, Colombia, and Peru.

As an example, Figure 2 presents the most relevant topics found in some of the countries of the three different regions.
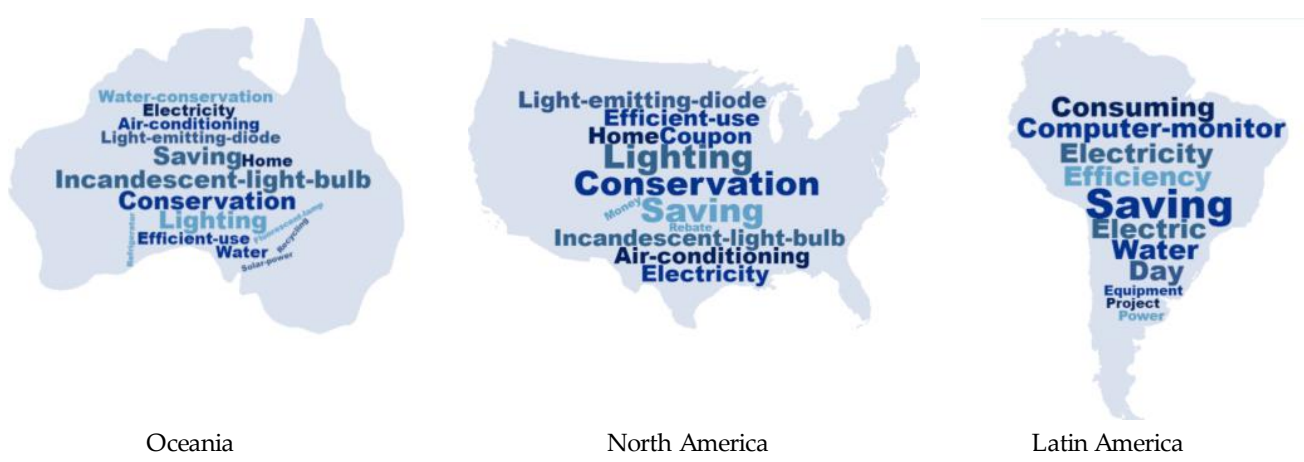

Figure 2. Visual examples of topics related to "energy-saving" in three different regions.

Considering Figure 1, it is worth noting that, regardless of the region, most of the topics found were related to energy-saving electronic devices, whereas a minority of them were related to nature (e.g., "water").

3.2. What Are the Kinds of Webpages That People Found When They Looked for "Energy-Saving" on Google in the Different Countries?

The results for this question can be categorized based on the type of website, as elucidated below:

- Educational: sites that aim at increasing the level of understanding of their users about energy-saving and its impact on different spheres (e.g., economic, environmental, etc.);

- Commercial: sites that aim to sell a product or provide a service that relates to the topic of energy-saving;

- Non-profit organizations: sites that are independent of government insight, including non-governmental organizations;

- Media: any official newspaper or related media sites with news regarding energy-saving (e.g., online newspapers, magazines);

- Government: sites with a governmental URL domain in accordance with each country;

- Wikipedia: any URL from this online encyclopedia.

Table 3 presents the results of this analysis with data grouped by region. The values correspond to the percentage of pages that belong to that category in that specific region; the sum is 100 for each region. 
Table 3. Google best-ranked webpages by economic status and region.

\begin{tabular}{ccccccc}
\hline Kind of Webpage & Educational & Commercial & $\begin{array}{c}\text { Non-Profit } \\
\text { Organization }\end{array}$ & Media & Government & Wikipedia \\
\hline Canada & $20 \%$ & $70 \%$ & $0 \%$ & $0 \%$ & $10 \%$ & $0 \%$ \\
USA & $30 \%$ & $40 \%$ & $0 \%$ & $0 \%$ & $30 \%$ & $0 \%$ \\
North America & $25 \%$ & $55 \%$ & $0 \%$ & $0 \%$ & $20 \%$ & $0 \%$ \\
Ireland & $20 \%$ & $50 \%$ & $0 \%$ & $10 \%$ & $20 \%$ & $0 \%$ \\
Spain & $40 \%$ & $10 \%$ & $20 \%$ & $0 \%$ & $30 \%$ & $0 \%$ \\
UK & $20 \%$ & $60 \%$ & $0 \%$ & $10 \%$ & $10 \%$ & $0 \%$ \\
Europe & $27 \%$ & $40 \%$ & $6 \%$ & $7 \%$ & $20 \%$ & $0 \%$ \\
Australia & $20 \%$ & $40 \%$ & $0 \%$ & $0 \%$ & $30 \%$ & $10 \%$ \\
New Zealand & $20 \%$ & $50 \%$ & $0 \%$ & $0 \%$ & $30 \%$ & $0 \%$ \\
Oceania & $20 \%$ & $45 \%$ & $0 \%$ & $0 \%$ & $30 \%$ & $5 \%$ \\
Hong Kong & $20 \%$ & $10 \%$ & $0 \%$ & $0 \%$ & $60 \%$ & $10 \%$ \\
India & $80 \%$ & $10 \%$ & $0 \%$ & $0 \%$ & $10 \%$ & $0 \%$ \\
Singapore & $20 \%$ & $40 \%$ & $0 \%$ & $20 \%$ & $20 \%$ & $0 \%$ \\
Asia & $40 \%$ & $20 \%$ & $0 \%$ & $7 \%$ & $30 \%$ & $3 \%$ \\
Argentina & $40 \%$ & $20 \%$ & $10 \%$ & $30 \%$ & $0 \%$ & $0 \%$ \\
Chile & $20 \%$ & $40 \%$ & $20 \%$ & $20 \%$ & $0 \%$ & $0 \%$ \\
Colombia & $40 \%$ & $30 \%$ & $10 \%$ & $10 \%$ & $10 \%$ & $0 \%$ \\
Mexico & $30 \%$ & $20 \%$ & $10 \%$ & $10 \%$ & $30 \%$ & $0 \%$ \\
Peru & $60 \%$ & $0 \%$ & $0 \%$ & $20 \%$ & $20 \%$ & $0 \%$ \\
Venezuela & $30 \%$ & $10 \%$ & $0 \%$ & $40 \%$ & $20 \%$ & $0 \%$ \\
Latin America & $38 \%$ & $20 \%$ & $7 \%$ & $22 \%$ & $13 \%$ & $0 \%$ \\
South Africa & $30 \%$ & $40 \%$ & $0 \%$ & $0 \%$ & $10 \%$ & $20 \%$ \\
Africa & $30 \%$ & $40 \%$ & $0 \%$ & $0 \%$ & $10 \%$ & $20 \%$ \\
\hline
\end{tabular}

Notably, a greater proportion of sites in developed regions (North America, Europe, Oceania) was of a commercial nature (46\%), whereas those of an educational nature (37\%) prevailed in developing regions (Latin America, Asia, Africa). It should be noted that in India and Peru, the majority of websites are educational ( $80 \%$ and $60 \%$, respectively). Overall, an important difference found among media-related sites was that they amounted to only $3 \%$ of the results in developed regions, whereas they totaled $15 \%$ of results in developing ones (mainly Latin America).

\subsection{What Are the Kinds of Images That People Found When They Looked for "Energy-Saving" on Google in the} Different Countries?

As noted in the methods, answering this question involved the identification of images, the analysis of features (labels) with Google API Vision through memespector, identification of the 95th percentile of the labels, the definition of a type of image taxonomy, and a manual classification of the images based on the taxonomy. As a result, it was found that the images related to the topic of energy-saving could be classified as follows:

- Electronic devices: images that have the use of electricity and/or various electronic elements for their functioning in common. Examples of this category include speakers, mobile phones, tablets, computers, laptops, washing machines, televisions, screens, switches, monitors, mini splits, batteries, and power sources. This category also includes energy generation devices such as solar cells, wind turbines, and windmills;

- Human: shapes or images that allude to the human figure, such as human shapes and human body parts like hands, fingers, eyes, and fingerprints, among others;

- Nature: shapes or figures that allude to elements of nature like the sun, trees, leaves, plants, grass, rain, wind, and diverse flora and fauna, among others;

- Infographics: figures or images that represent a collection of information in a graphic manner. Examples of this include infographics with statistics, processes, geography, characteristics, comparisons, and varieties, among others; 
- Products: objects or images in which the main component is a product or service that is displayed for commercial purposes; this image makes a clear and direct reference to a brand, a package, or a set of characteristics thereof (e.g., solar cells, energy-saving lamps, and lamp batteries);

- Money: refers to images where the focus involves economic exchange and trade agents, such as coins, bills, peso signs, payments, invoices, and piggy banks, as well as other symbols related to savings and the use of money;

- Illumination: comprises images or objects that refer to shapes of/or equipment that provides artificial lightning. Examples include spotlights or electric bulbs, street lighting, lamps, and any other objects that produce artificial light;

- Home: images or figures that allude to the various elements that make up a home (e.g., the shape of a house, kitchens, living or dining rooms, bedrooms, garages, bathrooms, furniture, or decorations);

- Transportation: includes figures or elements that refer to various vehicles or means of transporting people or objects (e.g., bicycles, cars, buses, trucks, trams, trains, etc.).

Table 4 presents the results for this analysis grouped by region. The values correspond to the percentage of images that belong to that category in that specific region; the sum is not 100 for each region since the images do not belong to just a single category.

The most popular Google images produced for the query "energy-saving" related to nature and lighting products. Notably, many of the images contained both elements, i.e., they made use of features from nature to promote lighting products and other household appliances. Remarkably, the images that alluded to natural lighting options were much more present in developed regions than in developing ones. Images with money-related elements were found in both groups, but appeared in a greater proportion in developed regions. 
Table 4. Images found by Google Search with the keyword "energy-saving".

\begin{tabular}{|c|c|c|c|c|c|c|c|c|c|c|c|c|c|c|c|c|c|c|c|c|c|c|c|c|}
\hline & 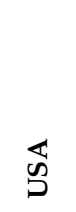 & 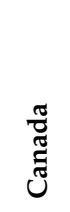 & 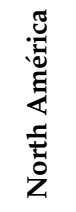 & 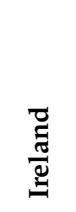 & $\begin{array}{l}\text { శึ } \\
\text { के }\end{array}$ & 光 & 苂 & 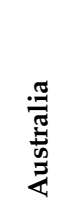 & 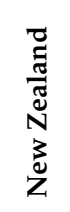 & 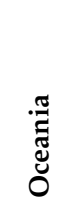 & 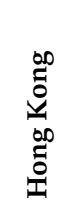 & 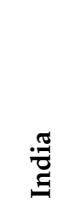 & 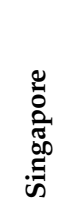 & $\frac{\pi}{2}$ & 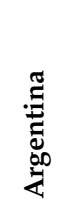 & 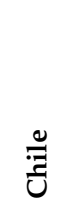 & $\frac{\pi}{0}$ & $\frac{8}{\stackrel{8}{x}}$ & 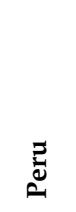 & 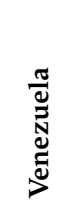 & 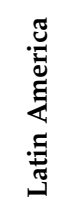 & 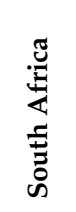 & 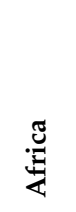 & $\begin{array}{l}\overline{0} \\
\stackrel{0}{0} \\
0\end{array}$ \\
\hline Electronic Devices & $18 \%$ & $8 \%$ & $13 \%$ & $40 \%$ & $38 \%$ & $16 \%$ & $31 \%$ & $20 \%$ & $10 \%$ & $15 \%$ & $14 \%$ & $26 \%$ & $8 \%$ & $16 \%$ & $14 \%$ & $14 \%$ & $32 \%$ & $16 \%$ & $28 \%$ & $18 \%$ & $20 \%$ & $12 \%$ & $12 \%$ & $18 \%$ \\
\hline Human & $14 \%$ & $20 \%$ & $17 \%$ & $30 \%$ & $18 \%$ & $14 \%$ & $21 \%$ & $22 \%$ & $14 \%$ & $18 \%$ & $24 \%$ & $18 \%$ & $14 \%$ & $19 \%$ & $14 \%$ & $8 \%$ & $22 \%$ & $20 \%$ & $58 \%$ & $20 \%$ & $24 \%$ & $14 \%$ & $14 \%$ & $19 \%$ \\
\hline Nature & $66 \%$ & $42 \%$ & $54 \%$ & $56 \%$ & $52 \%$ & $48 \%$ & $52 \%$ & $42 \%$ & $28 \%$ & $35 \%$ & $38 \%$ & $42 \%$ & $26 \%$ & $35 \%$ & $46 \%$ & $34 \%$ & $36 \%$ & $62 \%$ & $58 \%$ & $52 \%$ & $48 \%$ & $30 \%$ & $30 \%$ & $42 \%$ \\
\hline Infographics & $12 \%$ & $12 \%$ & $12 \%$ & $34 \%$ & $10 \%$ & $6 \%$ & $17 \%$ & $8 \%$ & $14 \%$ & $11 \%$ & $22 \%$ & $10 \%$ & $6 \%$ & $13 \%$ & $30 \%$ & $22 \%$ & $34 \%$ & $52 \%$ & $12 \%$ & $8 \%$ & $26 \%$ & $2 \%$ & $2 \%$ & $13 \%$ \\
\hline Products & $2 \%$ & $20 \%$ & $11 \%$ & $16 \%$ & $0 \%$ & $18 \%$ & $11 \%$ & $12 \%$ & $20 \%$ & $16 \%$ & $22 \%$ & $14 \%$ & $26 \%$ & $21 \%$ & $18 \%$ & $24 \%$ & $4 \%$ & $22 \%$ & $2 \%$ & $20 \%$ & $15 \%$ & $24 \%$ & $24 \%$ & $16 \%$ \\
\hline Money & $12 \%$ & $12 \%$ & $12 \%$ & $6 \%$ & $10 \%$ & $4 \%$ & $7 \%$ & $8 \%$ & $2 \%$ & $5 \%$ & $0 \%$ & $0 \%$ & $6 \%$ & $2 \%$ & $8 \%$ & $4 \%$ & $10 \%$ & $10 \%$ & $6 \%$ & $4 \%$ & $7 \%$ & $6 \%$ & $6 \%$ & $6 \%$ \\
\hline Illumination & $58 \%$ & $66 \%$ & $62 \%$ & $44 \%$ & $50 \%$ & $60 \%$ & $51 \%$ & $60 \%$ & $72 \%$ & $66 \%$ & $58 \%$ & $54 \%$ & $64 \%$ & $59 \%$ & $46 \%$ & $70 \%$ & $78 \%$ & $60 \%$ & $40 \%$ & $52 \%$ & $58 \%$ & $70 \%$ & $70 \%$ & $61 \%$ \\
\hline Home & $12 \%$ & $10 \%$ & $11 \%$ & $28 \%$ & $12 \%$ & $8 \%$ & $16 \%$ & $6 \%$ & $10 \%$ & $8 \%$ & $4 \%$ & $6 \%$ & $4 \%$ & $5 \%$ & $4 \%$ & $4 \%$ & $8 \%$ & $8 \%$ & $12 \%$ & $4 \%$ & $7 \%$ & $10 \%$ & $10 \%$ & $9 \%$ \\
\hline Transportation & $2 \%$ & $2 \%$ & $2 \%$ & $2 \%$ & $4 \%$ & $2 \%$ & $3 \%$ & $2 \%$ & $2 \%$ & $2 \%$ & $2 \%$ & $0 \%$ & $2 \%$ & $1 \%$ & $0 \%$ & $0 \%$ & $4 \%$ & $0 \%$ & $8 \%$ & $4 \%$ & $3 \%$ & $0 \%$ & $0 \%$ & $2 \%$ \\
\hline
\end{tabular}




\section{Discussion and Conclusions}

One of the main challenges facing contemporary society is environmental sustainability and the disinterested behavior that some people exhibit regarding this issue. It is common to come across people with no apparent interest in taking care of their environmental health. From a distance, it is difficult to understand this lack of motivation, since the environment is fundamental for fulfilling our everyday needs. Even though this is a global problem, energy-saving is a pro-environmental behavior to which every single person can contribute.

The importance that people devote to energy-saving, as a way of taking care of the planet and achieving sustainability, may be influenced by the information that they consume on the Internet. That is why recognizing the characteristics of such information is of vital importance.

Although most topics related to energy-saving in Google Trends across regions were promotions of commercial products, it was notable that topics associated with money predominated in developed countries, which allocated more importance to the environment, whereas developing countries were more closely linked to topics more closely related to nature, such as water. Along the same lines, commercial sites dominated the webpages ranked by Google (with the query "energy-saving") in developed regions (North America and Europe), whereas the educational sites were prevalent in developing regions (Latin America, Asia, and Africa). This phenomenon could be perceived as being reflective of different positions on a learning curve surrounding pro-environmental behavior based on the pervasiveness of messages promoting the importance of the environment in developed countries, which might lead to a greater focus on saving energy, whereas the developing countries are perceived as being in need of further education on this issue. In this regard, there is still much to be learned in developing countries. The good news is that there are indicators that they are working toward its achievement.

Google's image rankings varied slightly between countries, such that images in the developed countries were more related to new lighting technologies (e.g., LED bulbs) and images in the developing countries were more often associated with household appliances with many years in the market (refrigerators). However, nature-related images were used to persuade people to buy those products in all the countries. Beyond the clear strategy of commercial persuasion, this phenomenon might be an indication of an assumption by advertisers that citizens are well-aware of the relationship between saving energy and caring for the planet.

In this research, we detected that most information we found on the Internet related to energy-saving was associated with a commercial purpose. It was worth noting that even the majority of nature-filled images were part of product propaganda. This does not necessarily mean that most of the information on the Internet related to the aforementioned topic has commercial purposes, only that the contents found through search engines (in this case Google) are of this type. This relates to the way in which Google's indexing algorithms impact the content that search engines return, and to the website's purpose.

Moreover, what was found in this research may reflect what Van Dijck considered the possible outcome of the digital transformation of sociability: an industry whose progress is based on the value of metadata is a valuable resource whose potential that can be exploited. While it is believed that metadata obtained from platforms such as Google reflect human behavior as it occurs, its own algorithms and other sites are intrinsically selective and manipulative [3]. In this sense, non-commercial sites may have to pay more attention to this aspect if they want their content to compete with those that seek to sell an energy-saving product.

However, perhaps the phenomenon that manifests among Internet users around the relationship between well-being, environment, energy-saving, and money is similar to behaviors derived from the relationship between health, food, healthy eating, and weight. Many people choose to consume certain foods with the aim of maintaining weight (immediate cause), although it is perhaps more important that this action helps maintain health (final cause) in the long-term. In the same manner, Internet users seem to relate energy-saving with the saving of money (immediate cause), and this action helps to 
take care of the planet, thus contributing to our well-being (final cause), even if the latter goal is not a motivating factor.

In any case, efforts to save energy are good news, regardless of the motivation. However, very little evidence was found in this study regarding ways of saving energy in which the purchase of products was not involved. Practices such as turning off the lights, riding bicycles or using public transportation, and conserving water, among others, could help the environment as much as buying products with a better energy efficiency. Therefore, it seems that a pending goal is to avoid leaving the task of raising awareness about the importance of saving energy solely in the hands of commercial interests. In this sense, facilitating pro-environmental practice does not depend only on the will of individuals, but also requires the involvement of governmental and educational institutions.

These conclusions should be analyzed considering the limitations of this research, one of which was the imbalance in regional representation due to the language restriction of our inclusion criteria (e.g., only one African country was included, whereas North America had a complete representation). A possible future study may tackle this restriction by including a balanced number of countries, regardless of their language. Furthermore, we only searched for the terms in one search engine (i.e., Google), and perhaps different results could arise from searching for them in other ones, like Yahoo or Bing, among others.

Author Contributions: R.R. contributed by defining the methodology and supervising the data collection. G.V.-U. wrote the paper, and collected and analyzed data.

Funding: This research was funded by the Project 266632 "Laboratorio Binacional para la Gestión Inteligente de la Sustentabilidad Energética y la Formación Tecnológica" [Binational Laboratory for the Intelligent Management of the Energy Sustainability and the Technological Formation], with funds from the energy sustainability fund CONACYT-SENER (Agreement: S0019-2014-01).

Conflicts of Interest: The authors declare no conflicts of interest.

\section{References}

1. OECD. Compendium of OECD Well-Being Indicators. Available online: https://www.oecd.org/general/ compendiumofoecdwell-beingindicators.htm (accessed on 5 August 2019).

2. He, W.; Fang, Y.; Malekian, R.; Li, Z. Time Series Analysis of Online Public Opinions in Colleges and Universities and its Sustainability. Sustainability 2019, 11, 3546. [CrossRef]

3. Van Dijck, J. In data we trust? The implications of datafication for social monitoring. MATRIZes 2017, 11, 39-59. [CrossRef]

4. Brunn, S. Cyberspace Knowledge Gaps and Boundaries in Sustainability Science: Topics, Regions, Editorial Teams and Journals. Sustainability 2014, 6, 6576-6603. [CrossRef]

5. Wilson, E.O. Biophilia; Harvard University Press: Cambridge, MA, USA, 1984; p. 176. ISBN 978-0-674-07442-2.

6. Beatley, T. Biophilic Cities: Integrating Nature into Urban Design and Planning, 2nd ed.; Island Press: Washington, DC, USA, 2010; ISBN 978-1-59726-715-1.

7. Prati, G.; Albanesi, C.; Pietrantoni, L. Social Well-Being and Pro-Environmental Behavior: A Cross-Lagged Panel Design. Hum. Ecol. Rev. 2017, 23, 123-140. [CrossRef]

8. Hori, S.; Kondo, K.; Nogata, D.; Ben, H. The determinants of household energy-saving behavior: Survey and comparison in five major Asian cities. Energy Policy 2013, 52, 354-362. [CrossRef]

9. Kollmuss, A.; Agyeman, J. Mind the Gap: Why do people act environmentally and what are the barriers to pro-environmental behavior? Environ. Educ. Res. 2002, 8, 239-260. [CrossRef]

10. World Commission on Environment and Development. Our Common Future; Oxford University Press: Oxford, UK; New York, NY, USA, 1987; ISBN 978-0-19-282080-8.

11. Strange, T.; Bayley, A. OECD Insights: Sustainable Development: Linking Economy, Society, Environment; OECD: Paris, France, 2009; ISBN 978-92-64-04778-5.

12. Mittal, M.K.; Kirar, N.; Meena, J. Implementation of Search Engine Optimization: Through White Hat Techniques. In Proceedings of the 2018 International Conference on Advances in Computing, Communication Control and Networking (ICACCCN), Greater Noida (UP), India, 12-13 October 2018; pp. 674-678. 
13. Search Engine Optimization. Available online: https://www.optimizely.com/optimization-glossary/searchengine-optimization/ (accessed on 5 August 2019).

14. Search Engine Market Share Worldwide. Available online: http://gs.statcounter.com/search-engine-marketshare (accessed on 5 August 2019).

15. Zaghoul, F.A.; Rababah, O.; Fakhouri, H. Website Search Engine Optimization: Geographical and Cultural Point of View. In Proceedings of the 2014 UKSim-AMSS 16th International Conference on Computer Modelling and Simulation, Cambridge, UK, 26-28 March 2014; pp. 452-455.

16. Rogers, R. Digital Methods for Web Research. In Emerging Trends in the Social and Behavioral Sciences; John Wiley \& Sons, Inc.: Hoboken, NJ, USA, 2015; pp. 1-22, ISBN 978-1-118-90077-2.

17. Rogers, R. Digital Methods; The MIT Press: Cambridge, MA, USA, 2015; ISBN 978-0-262-52824-5.

18. Gillian, R. Visual Methodologies: An Introduction to Researching with Visual Materials; SAGE Publications: Thousand Oaks, CA, USA, 2016; ISBN 978-1-4739-6791-5.

19. Perdue, R.T.; Hawdon, J.; Thames, K.M. Can Big Data Predict the Rise of Novel Drug Abuse? J. Drug Issues 2018, 48, 508-518. [CrossRef]

20. Park, S.; Kim, J. The effect of interest in renewable energy on US household electricity consumption: An analysis using Google Trends data. Renew. Energy 2018, 127, 1004-1010. [CrossRef]

21. NetMarketShare. Market Share for Mobile, Browsers, Operating Systems and Search Engines. Available online: https://netmarketshare.com/ (accessed on 5 August 2019).

22. Vaughan, L. Discovering business information from search engine query data. Online Inf. Rev. 2014, 38, 562-574. [CrossRef]

23. Green, H.K.; Edeghere, O.; Elliot, A.J.; Cox, I.J.; Morbey, R.; Pebody, R.; Bone, A.; McKendry, R.A.; Smith, G.E. Google search patterns monitoring the daily health impact of heatwaves in England: How do the findings compare to established syndromic surveillance systems from 2013 to 2017? Environ. Res. 2018, 166, 707-712. [CrossRef] [PubMed]

24. Mulfari, D.; Celesti, A.; Fazio, M.; Villari, M.; Puliafito, A. Using Google Cloud Vision in assistive technology scenarios. In Proceedings of the 2016 IEEE Symposium on Computers and Communication (ISCC), Messina, Italy, 27-30 June 2016; pp. 214-219.

25. Hyam, R. Automated Image Sampling and Classification Can Be Used to Explore Perceived Naturalness of Urban Spaces. PLoS ONE 2017, 12, e0169357. [CrossRef] [PubMed]

26. Mintz, A. Memespector (Python Version). Available online: https://github.com/amintz/memespector-python (accessed on 5 August 2019).

27. Hosseini, H.; Xiao, B.; Poovendran, R. Google's Cloud Vision API is Not Robust to Noise. In Proceedings of the 2017 16th IEEE International Conference on Machine Learning and Applications (ICMLA), Cancun, Mexico, 18-21 December 2017; pp. 101-105. 